\title{
ENDÜSTRİYEL TAV FIRINLARINDA ENERJİ TASARRUFU VE EMİSYON AZALTIM FIRSATLARI
}

\author{
Muharrem EYİDOĞAN*, Durmuş KAYA**, Şükrü DURSUN ${ }^{* *}$, Osman TAYLAN** \\ "Karabük Üniversitesi Enerji ve Çevre Teknolojileri Birimi, Karabük \\ ${ }^{* *}$ Department of Industrial Engineering, College of Engineering, King Abdulaziz University, Jeddah, Saudi \\ Arabia \\ muharrem evidogan@hotmail.com, durmuskava@hotmail.com, sdursun@selcuk.edu.tr, \\ otaylan@kau.edu.sa
}

(Geliş/Received: 23.12.2013; Kabul/Accepted: 11.09.2014)

ÖZET

Bu çalışmada, bir sanayi kuruluşunun LNG (sıvılaştırılmış doğalgaz) yakıtlı haddehane tav firınında enerji verimliliği çalışması yapılmıştır. Bu kapsamda firın işletme koşullarında çalışırken sıcaklık, basınç, hız ve yanma gazı ölçümleri yapılmış, ölçüm verileri kullanılarak kütle ve enerji dengesi kurulmuştur. Yapılan hesaplamalarda; firın genel verimi \%52,76 olarak bulunmuştur. Başlıca verim kayıpları; fırının yüksek hava fazlalık katsayısıyla çalıştırılması, reküperatör ısı transfer yüzey alanının yetersiz kalması ve firın yüzeyi ısı kayıpları olarak belirlenmiştir.

Anahtar Kelimeler: Haddehane tav fırını, reküperatör, enerji verimliliği, enerji tasarrufu, atık ısı geri kazanımı, emisyon azaltımı

\section{ENERGY SAVING AND EMISSION REDUCTION OPPORTUNITIES IN AN INDUSTRIAL ANNEALING FURNACES}

\begin{abstract}
In this study, "energy efficiency" study has been performed for a LNG (Liquefied Natural Gas) fuel annealing furnace. Within this frame, temperature, pressure, velocity, and gas analysis measurements have been made and energy and mass balances have been formed. From the measured data, the furnace total efficiency was calculated as $52.76 \%$. The main efficiency losses: operating furnace at high air excessiveness coefficient, inadequacy of air preheater heater (recuperator) heat transfer surface area and surface thermal losses.
\end{abstract}

Author keywords: Annealing furnace, recuperator, energy efficiency, energy saving, waste heat recovery, emission reduction

\section{GÍRISŞ (INTRODUCTION)}

Enerjinin verimli kullanımı, tüm dünyada üzerinde önemle durulan konulardan biridir. Enerji üretimi ve kullanımının, hava kirliliği, sera gazı etkisi ve ekosisteme etkileri gibi birçok çevresel etkisi vardır [1]. Uluslararası enerji ajansının raporuna göre enerji üretiminden kaynaklanacak $\mathrm{CO}_{2}$ emisyonunun 2030 yılında, 2005 yılına göre $\% 49$ artacağı ve birçok ülkenin orta ve uzun vadede yüksek enerji fiyatı ile karşı karşıya kalacağı ifade edilmiştir [2]. Endüstriyel işletmeler açısından bakıldığında, verimliliği arttırıcı çalışmalar yakıttan tasarruf sağlamakta, kaynakların verimli kullanımına ve çevre kirliliğinin azaltılmasına önemli ölçüde katkıda bulunmaktadır $[3,4]$.

Demir-çelik sektörü yıllık yaklaşık 24 EJ (24x1018 J) enerji tüketimi ile en çok enerji tüketen sektörlerden birisidir ve bu tüketim dünyanın toplam enerji tüketiminin \%5'ine karşl1ık gelmektedir [5]. Sektörün Üretim maliyetleri içerisinde \%27-33'lük pay ile en büyük dilimi alan enerji maliyetleri, ürün maliyetlerinin düşürülmesinde hedef alınan birincil kaynak olmaktadır. Fırınlar, özellikle yüksek sıcaklıklarda çalışan tavlama firınları, endüstriyel işletmelerde gerek yakıt tüketimi açısından gerekse 
bacadan atılan yanma gazlarının oluşturduğu kirlilik açısından mümkün olduğunca verimli çalıştırılması gereken sistemlerdir.

Fırınlarda enerji verimliliğine yönelik birçok çalışma yapılmıştır. Ertem ve ark. [6] yaptıkları çalışmada Ereğli Demir ve Çelik Fabrikaları'nın 3 nolu yassı kütük fırınında kullanılan özgül enerjinin iyileştirilmesi potansiyelini incelemişlerdir. Prosesteki kayıp enerjinin hesaplanması için bir enerji giriş ve çıkış modeli oluşturmuşlar ve yassı kütük firınının enerji verimliliğini \%64,26 olarak hesaplamışlardır. Yapılan çalışmada enerji tasarrufu potansiyeli olarak fırına şarj edilen kütüklerin sıcak şarj edilmesi ve reküperatörden sonra atılan baca gazı 1sısının geri kazanılmasını belirlemişlerdir. Baca gazının enerji potansiyelini $81.590 \quad \mathrm{kcal} / \mathrm{TEP}$ olarak hesaplamışlardır. Ertem ve ark. [7] yaptıkları çalışmada endüstriyel tav fırınlarında enerji kaybının görüldüğü başlıca kısımları incelemiş, enerji verimlilik analizi yapmış, isıl verimi bulmuş ve kayıpları tespit etmişlerdir. Giren enerji ile ürüne aktarılan enerji arasındaki farkın hangi tür kayıplar olduğu ve miktarları belirlenmiștir. Çalışma sonucunda 1sil verim \%38,3 olarak bulunmuştur. Kayıplar ise \%31,6 ile baca gazı kayıpları, \%10,4 ile yüzey kayıpları, \%13 ile açıklık kayıpları ve \%6,7 ile diğer kayıplar olarak belirlenmiştir. Si ve ark. [8] yaptıkları çalışmada Kanada, Manitoba'da bulunan bir çelik fabrikasının enerji verimliliğini değerlendirmiş ve atık 1Sı geri kazanımının olabilirliğini analiz etmişlerdir. Proses 1sıtma değerlendirmesi ve gözden geçirme aracı (PHAST) ile yapılan çalışmada tav fırını verimi $\% 60$ olarak hesaplanmıştır. Çalışmada baca gazı kayıpları toplam enerji kayıplarının \%29,5'i ile tav firınındaki en büyük enerji kaybını oluşturmuştur. Çalışma sonucunda enerji verimliliğinin artırılması için kütüklerin $315^{\circ} \mathrm{C}$ 'ye ön ısıtılması gerektiği belirtilmiştir. Chen ve ark. [9] yaptıkları çalışmada bir sıcak haddehanenin tav firınlarının performansını ve enerji tüketimini hem sayısal tahminler hem de pratik ölçümler ile analiz etmişlerdir. Sayısal tahminlerde fırınların artan üretim hızının yakıtı daha verimli olarak kullandığını göstermiştir. Pratik çalışma ise fırın içerisindeki ısının \%80'inin yakıtın yanması, \%15,7'sinin ise sicak baca gazı ile sağlandığını göstermiştir. Ayrıca pratik ölçümler 1Sı geri kazanımı bölgesindeki 1Sı değișimi ve 1 s 1 geri kazanımı verimlerinin sirasıly $\% 86,66$ ve $\% 47,76$ olduğunu göstermiştir. Manatura ve Tangtrakul [10] yaptıkları çalışmada reküperatör ile birleştirilmiş rejeneratif burner'lerin (yakıcıların) kullanıldığg bir tav firınında enerji kullanımını incelemişlerdir. Yapılan çalışmada tav fırınının özgül enerji tüketimi $1.042 \mathrm{MJ} / \mathrm{t}$ olarak bulunmuş ve firın verimi \%80,1 olarak hesaplanmıştır. Çalışmada enerji tasarruf oranı sadece reküperatör kullanılan tav firınları ile karşılaştırıldığında \% 43,4 olarak bulunmuş ve rejeneratif burner ile önemli bir verim değeri elde edilmiştir.
Literatürde yapılan çalışmalarda [6-10] tav fırınlarında enerji verimleri işletme verileri kullanılarak hesaplanmalar yapılmış ve tasarruf imkânları belirlemişlerdir. Ancak çalışmalar sahada yapılan detaylı enerji verimliliği ölçüm ve etütlerine dayanmamıştır. $\mathrm{Bu}$ çalışmada ise bir sanayi kuruluşunun LNG ile çalışan tav fırınında enerji verimliliğine yönelik detaylı ölçümler yapılmış, ölçüm sonuçları ve firmadan alınan verileri kullanılarak kütle ve enerji dengesine yönelik hesaplamalar yapılmış, enerji tasarruf imkânları ve boyutları geri ödeme süreleriyle birlikte belirlenmiştir.

\section{2. ÖLÇÜM YÖNTEMI VE ÖLÇÜM CIHAZLARI (MEASUREMENT METHOD AND DEVICES)}

Tav firınlarının ısıl veriminin hesaplanmasında direkt ve dolaylı yöntem olmak üzere iki yöntem kullanılmaktadır; Direkt yöntemde ısıl verim, malzemenin aldığı ısının, kullanılan yakıt ısısına bölünmesi ile hesaplanmaktadır. $\mathrm{Bu}$ yöntemde aşağıdaki ölçümler gerçekleştirilmelidir;

- Fırına giren ve çıkan kütük miktarları,

- Kütüğün firına giriş ve çıkış sıcaklığı,

- Yakıt besleme miktarı,

- Yakıtın alt isıl değeri.

$\mathrm{Bu}$ ölçümler doğrultusunda 1sıl verim ifadesi genel olarak şu şekilde verilebilir:

$\eta=\frac{m_{k} c_{p 2} T_{2}-m_{k} c_{p 1} T_{1}}{B H u}$

Dolaylı yöntemde ise 1sıl verim, firın kayıplarının çıkarılması ile hesaplanabilmektedir.

$\eta=1-\sum Z$

Bu kayıplar; baca gazı kayıpları, açıklık kayıpları, tufal kayıpları, duvar kayıpları, soğutma suyu kayıpları ve diğer hesaplanmayan kayıplardır [11].

Dolaylı yöntemle ısıl verim hesaplanırken aşağıdaki ölçümler gerçekleştirilmeli ve sonuç verileri göz önüne alınmalıdır:

- Fırına giren ve çıkan kütük miktarları,

- Fırına giren ve çıkan kütük sıcaklıkları,

- Yakit besleme miktarı,

- Yakıtın alt 1sıl değeri ve elementel analizi,

- Baca gazı analizi (baca gazında sıcaklık, hız, basınç ve gaz ölçümleri),

- Yakma havası sıcaklığı,

- Firın sıcaklığı,

- Firın diş cidar sıcaklıkları,

- Reküperatör öncesi ve sonrası egzoz gazı sicaklığ 1 ,

- Reküperatör öncesi ve sonrası oksijen oranı,

- Soğutma suyu debisi,

- Soğutma suyu giriș ve çıkış sıcaklıkları. 
Fırında; fırın giriş ve çıkışı ile reküperatör giriş ve çıkışı arasında kütle ve enerji dengesinin kurulabilmesi için akışlara ait hız, basınç, sıcaklık ve yanma gazı ölçümleri yapılmış, ayrıca sistem üzerindeki mevcut kalibrasyonlu sayaçlardan değerler okunmuştur. Ölçülen değerler ile mevcut sayaçlardan alınan değerler kütle ve enerji dengelerinin kurulmasında kullanılmıştır. Fırının çalışma sistemi Şekil 1'de şematik olarak gösterilmiştir.

Fırında yakıt olarak kullanılan LNG (sıvılaştırılmış doğal gaz) debileri SCADA ekranından alınmıştır. LNG'nin içeriği kullanılarak yanma ürünlerinin bileşenleri ve debileri hesap edilmiştir. Hesap edilen teorik değerler, firın çıkışı ve baca çıkışında yapılan gaz analizi, basınç, hız ve sıcaklık ölçümleriyle de karşılaştırılmış ve doğrulukları kontrol edilmiştir. Yakıt içeriğine göre teorik hava miktarı belirlenirken aşağıdaki denklemler (3-6) kullanılmıştır.

Teorik (stokiyometrik) yakma hava miktarı hesabı

$\mathrm{CH}_{4}+2 \mathrm{O}_{2} \rightarrow \mathrm{CO}_{2}+2 \mathrm{H}_{2} \mathrm{O}$

$\mathrm{C}_{2} \mathrm{H}_{6}+7 / 2 \mathrm{O}_{2} \rightarrow 2 \mathrm{CO}_{2}+3 \mathrm{H}_{2} \mathrm{O}$

$\mathrm{C}_{3} \mathrm{H}_{8}+5 \mathrm{O}_{2} \longrightarrow 3 \mathrm{CO}_{2}+4 \mathrm{H}_{2} \mathrm{O}$

$\mathrm{C}_{4} \mathrm{H}_{10}+13 / 2 \mathrm{O}_{2} \rightarrow 4 \mathrm{CO}_{2}+5 \mathrm{H}_{2} \mathrm{O}$

Baca gazı, fırın çıkışı egzoz gazı ve reküperatör çıkışı egzoz gazı analizleri için elektrokimyasal detektör yöntemi ile çalışan TESTO 350S ve TESTO 350XL marka gaz analiz cihazları kullanılmıştır. TESTO 445 marka cihaz ile baca gazı hız ve basınç değerleri ölçülmüş ve baca gazı debileri hesaplanmıştır. Baca gazı debilerinin ölçümünden sonra, baca çıkışı $\mathrm{O}_{2}$ yüzdesi ve fırın çıkışı $\mathrm{O}_{2}$ yüzdelerinden faydalanılarak fırın yanma gazı debisi hesaplanmıştır. Sisteme beslenen kütük ve oluşan tufal miktarı bilgileri ise işletmeden alınmıştır. Ayrıca bunlara ait giriş ve çıkış sıcaklık değerleri sicaklık ölçüm cihazlarıyla belirlenmiştir.

\section{3. ÖLÇÜM VE HESAP SONUÇLARININ DEĞERLENDİRILMESİ (EVALUATION OF MEASUREMENT AND CALCULATION RESULTS)}

\section{1. Ölçüm Sonuçları (Measurement Results)}

Haddehane tav firını reküperatör öncesi ve sonrası oksijen oranı ve egzoz gazı sıcaklığı ölçüm değerleri ile yakıt debileri Tablo 1'de verilmiştir. Fırına beslenen LNG analiz değerleri Tablo 2'de sunulmuştur.

Tablo 1. Tav firını reküperatör öncesi ve sonrası ölçüm değerleri ve yakıt debileri (The measurement and fuel flow rate values before and after the recuperator in the annealing furnace)

\begin{tabular}{|l|c|c|}
\hline \multicolumn{3}{|c|}{ Haddehane Tav Firını } \\
\hline & $\mathrm{O}_{2}(\%)$ & Sicaklık $\left({ }^{\circ} \mathrm{C}\right)$ \\
\hline Reküperatör Öncesi & 8,64 & 587 \\
\hline Reküperatör Sonras1 & 8,64 & 458 \\
\hline LNG $\left(\mathrm{Nm}^{3} / \mathrm{h}\right)$ & \multicolumn{2}{|c|}{506} \\
\hline
\end{tabular}

Yakıt miktarı, fırın yanma gazı oksijen yüzdesi ve yakıtın elementel analizleri kullanılarak yanma gazı analizleri yapılmış ve sonuçlar Tablo 2'de verilmiştir. Teorik yakma havası ve yanma ürünlerini tespit etmek için 3-6 nolu denklemlerden yararlanılmıştır.

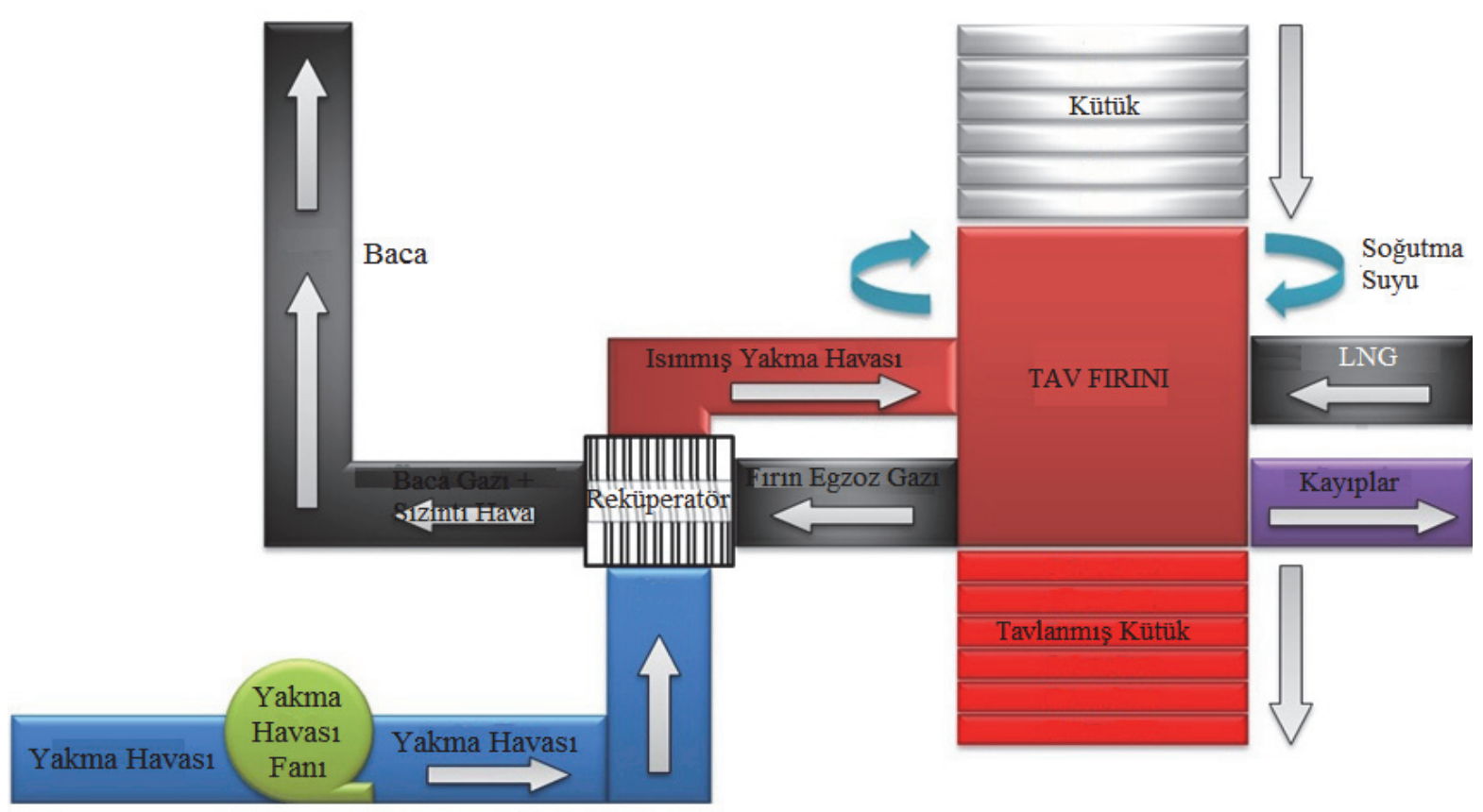

Şekil 1. Tav firını çalışma ve ölçüm sisteminin şematik gösterimi (Schematic representation of the annealing furnace operation and measurement systems) 
Tablo 2. Tav fırını LNG analizi, yanma ürünleri ve debileri (LNG analysis, combustion products and combustion gas flow rates of the annealing furnace)

\begin{tabular}{|l|c|c|c|c|c|c|c|c|}
\hline \multicolumn{4}{|c|}{ Yakıt } & \multicolumn{5}{c|}{ Yanma Ürünleri (Nm $\left.\mathbf{N m}^{\mathbf{3}}\right)$} \\
\hline Yakıt Analizi & \% (ob) & Stok. O & $\mathbf{C O}_{\mathbf{2}}$ & $\mathbf{N}_{\mathbf{2}}$ & Argon & $\mathbf{H}_{\mathbf{2}} \mathbf{O}$ & $\mathbf{O}_{\mathbf{2}}$ & Diğger \\
\hline $\mathrm{CH}_{4}$ & 94,9 & 960 & 482 & 3.579 & 43 & 1.044 & 0 & 0 \\
\hline $\mathrm{C}_{2} \mathrm{H}_{6}$ & 3,1 & 55 & 31 & 205 & 2 & 52 & 0 & 0 \\
\hline $\mathrm{C}_{3} \mathrm{H}_{8}$ & 1,0 & 25 & 15 & 94 & 1 & 22 & 0 & 0 \\
\hline $\mathrm{C}_{4} \mathrm{H}_{10}$ & 0,3 & 10 & 6 & 37 & 0 & 8 & 0 & 0 \\
\hline $\mathrm{CO}_{2}$ & 0,5 & 0 & 0 & 0 & 0 & 0 & 0 & 0 \\
\hline $\mathrm{N}_{2}$ & 0,2 & 0 & 3 & 0 & 0 & 0 & 0 & 0 \\
\hline Fazla hava (Nm/h) & & 1 & 3,123 & 37 & 73 & 838 & 0 \\
\hline Gaz Bileşimi \% (ob) & & 5,55 & 72,57 & 0,86 & 12,38 & 8,64 & 0.0 \\
\hline
\end{tabular}

Tablo 2'nin bileşenleri kullanılarak toplam stokiyometrik yanma gazı, teorik yakma havası, fazla hava, teorik toplam yanma havası, fırın çıkış gazı debileri, fazla hava oranı hesaplanmış ve Tablo 3 'de verilmiştir. Hesaplanan debiler, ayrıca baca çıkışında ölçülerek doğruluğu sağlanmıştır.

Tablo 3. Tav firını toplam yakma havası ve firın yanma gazı debileri (Total combustion air and combustion gas flow rates of the annealing furnace)

\begin{tabular}{|l|l|}
\hline \multicolumn{2}{|c|}{$\begin{array}{c}\text { Sistemin Toplam Yakma Havası ve Fırın } \\
\text { Yanma Gazı Debileri }\end{array}$} \\
\hline Teorik Yakma Havası $\left(\mathrm{Nm}^{3} / \mathrm{h}\right)$ & 5.106 \\
\hline Teorik Fırın Çıkışı Gaz Debisi $\left(\mathrm{Nm}^{3} / \mathrm{h}\right)$ & 5.626 \\
\hline Fazla Hava Miktarı $\left(\mathrm{Nm}^{3} / \mathrm{h}\right)$ & 4.073 \\
\hline Toplam Fırın Çıkışı Gaz Debisi $\left(\mathrm{Nm}^{3} / \mathrm{h}\right)$ & 9.699 \\
\hline Fırına Giren Hava $\left(\mathrm{Nm}^{3} / \mathrm{h}\right)$ & 9.179 \\
\hline Fazla Hava Oranı $(\%)$ & 79,77 \\
\hline
\end{tabular}

\subsection{Tav Fırını Verimi (The Annealing Furnace Efficiency)}

Tav fırını verimi; kütüğün kütlesel debisi, kütüğe verilen 1sı miktarı ve toplam yakıt 1sısı kullanılarak Denklem 1 ile verilen formülle hesaplanmış ve sonuçlar Tablo 4'de verilmiştir.
Tablo 4. Haddehane tav firını verimi (The annealing furnace efficiency)

\begin{tabular}{|l|r|}
\hline \multicolumn{2}{|c|}{ Tav Fırını Verimi } \\
\hline Yakıtın Alt Isıl Değeri $\left(\mathrm{kcal} / \mathrm{Nm}^{3}\right)$ & 8.414 \\
\hline Kütük debisi $\left(\mathrm{m}_{\mathrm{b}}, \mathrm{kg} / \mathrm{h}\right)$ & 13.900 \\
\hline Kütüğge verilen 1sı $\mathrm{Q}_{\mathrm{s}}(\mathrm{kcal} / \mathrm{h})$ & 2.276 .820 \\
\hline Tufalda kalan 1sı $(\mathrm{kcal} / \mathrm{h})$ & 28523 \\
\hline Kütükte kalan net $1 \mathrm{~s} 1 \mathrm{Q}_{\mathrm{s}}(\mathrm{kcal} / \mathrm{h})$ & 2.248 .297 \\
\hline Toplam yakıt $1 \mathrm{~s} 1 \mathrm{~s} 1 \mathrm{Q}_{\mathrm{y}}(\mathrm{kcal} / \mathrm{h})$ & 4.257 .484 \\
\hline Genel verim $\left.\mathbf{( \%}, \mathbf{Q}_{\mathbf{s}} / \mathbf{Q}_{\mathbf{y}}\right) \mathbf{\%}$ & $\mathbf{5 2 , 8 1}$ \\
\hline
\end{tabular}

\subsection{Sistemin Enerji ve Kütle Denklikleri (Energy and} Mass Balances of System)

Ölçülen değerler kullanılarak firın ve reküperatör için enerji-kütle denklikleri kurulmuş ve sonuçlar sırasıyla Tablo 5 ve Tablo 6'da verilmiştir. Tav firını toplam enerji ve kütle denkliği ise Tablo 7'de sunulmuştur. Tav firını ve reküperatör enerji dengeleri kullanılarak mevcut durumun Sankey diyagramı oluşturulmuş ve Şekil 2'de verilmiştir. Sankey diyagramından da görüleceği gibi firınına verilen enerjinin $\% 52,45^{\prime}$ i kütüklere aktarılmakta, \%8,35'i açıklık, izolasyon ve diğer kayıplar, \%37,86'sı bacadan yanma gazı ve $\% 1,34$ ise tufal ile 1 s1 kayb1 olarak atılmaktadır. Bacadan yanma gazı ile kaybedilen 1sının \%8,3'ü reküperatör ile geri kazanılmaktadır.

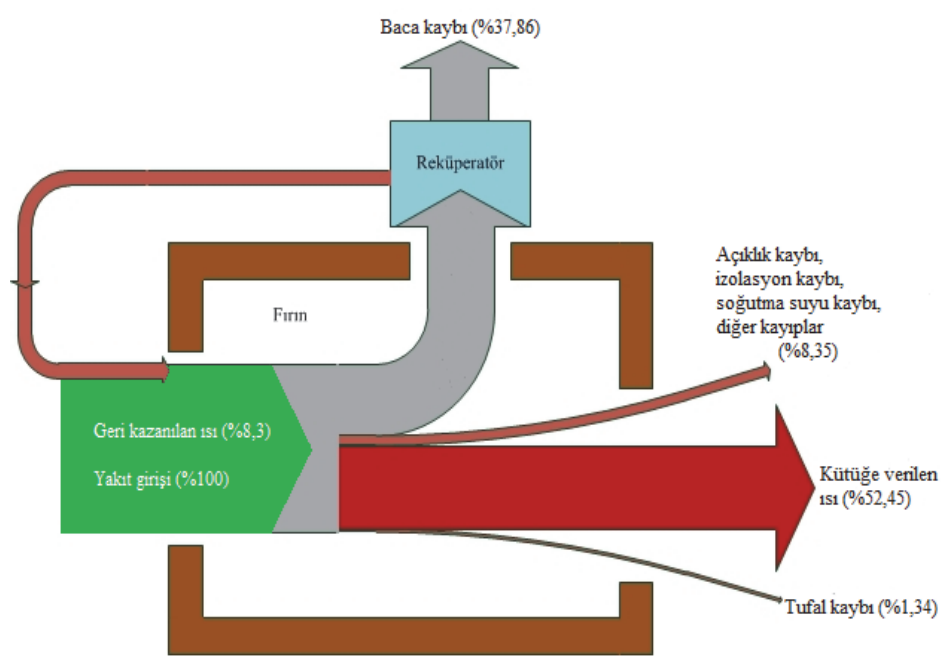

Sekil 2. Tav firını toplam enerji denkliği Sankey diyagramı (Sankey diagram of the annealing furnace total energy balance) 
Tablo 5. Haddehane tav firını enerji ve kütle denkliği (Energy and mass balance of the annealing furnace)

\begin{tabular}{|c|c|c|c|c|c|}
\hline \multicolumn{6}{|c|}{ Sistemin Toplam Enerji ve Kütle Denkliği } \\
\hline Girişler & $\begin{array}{c}\text { Debi } \\
\left(\mathrm{Nm}^{3} / \mathbf{h}\right)\end{array}$ & $\begin{array}{c}\text { Sicaklık } \\
\left({ }^{\circ} \mathrm{C}\right)\end{array}$ & $\underset{\left(\mathrm{kcal} / \mathrm{Nm}^{3} \mathrm{~K}\right)}{\mathrm{Cp}}$ & $\begin{array}{c}\mathbf{Q} \\
(\mathrm{kcal} / \mathrm{h})\end{array}$ & $\%$ \\
\hline LNG (Yakma Isısı) & 506 & & 8.414 & 4.257 .484 & 90,54 \\
\hline LNG (Duyulur Is1) & 506 & 18 & 0,43 & 3.916 & 0,08 \\
\hline $\begin{array}{l}\text { Firına Giren Yakma } \\
\text { Havası }\end{array}$ & 9.179 & 142 & 0,32 & 412.284 & 8,77 \\
\hline Kütük & $13.900^{*}$ & $18 * * *$ & $0,11 * *$ & 28.523 & 0,61 \\
\hline Toplam & & & & 4.702.207 & \\
\hline Çıkışlar & $\begin{array}{c}\text { Debi } \\
\left(\mathrm{Nm}^{3} / \mathbf{h}\right)\end{array}$ & $\begin{array}{c}\text { Sicaklık } \\
\left({ }^{\circ} \mathrm{C}\right)\end{array}$ & $\begin{array}{c}\mathrm{Cp} \\
(\mathrm{kcal} / \mathrm{Nm} 3 \mathrm{~K})\end{array}$ & $\begin{array}{c}\mathrm{Q} \\
(\mathrm{kcal} / \mathrm{h})\end{array}$ & $\%$ \\
\hline Kütük & $13.553^{*}$ & 1.050 & $0,16^{* *}$ & 2.276 .820 & 48,42 \\
\hline Fırın Çıkış Gazı & 9.699 & 587 & 0,38 & 2.163 .449 & 46,01 \\
\hline $\begin{array}{l}\text { Tufal Kaybı (\%2,5 } \\
\text { ölçülen) }\end{array}$ & $348^{*}$ & 1.050 & $0,16^{* *}$ & 58.380 & 1,24 \\
\hline $\begin{array}{l}\text { Diğer Kayıplar } \\
\text { (Açıklık kaybı, } \\
\text { duvar kaybı, vb.) }\end{array}$ & & & & 203.559 & 4,33 \\
\hline Toplam & & & & 4.702.207 & \\
\hline
\end{tabular}

Tablo 6. Tav firını reküperatörü enerji ve kütle denkliği (Energy and mass balance of the annealing furnace recuperator) Reküperatör Enerji ve Kütle Denkliği

\begin{tabular}{|c|c|c|c|c|c|}
\hline Girişler & $\begin{array}{c}\text { Debi } \\
\left(\mathrm{Nm}^{3} / \mathrm{h}\right)\end{array}$ & $\begin{array}{c}\text { Sicaklık } \\
\left({ }^{\circ} \mathrm{C}\right)\end{array}$ & $\begin{array}{c}\mathrm{Cp} \\
\left(\mathrm{kcal} / \mathrm{Nm}^{3} \mathrm{~K}\right)\end{array}$ & $\begin{array}{c}\mathbf{Q} \\
(\mathrm{kcal} / \mathrm{h})\end{array}$ & $\%$ \\
\hline Fırın Çıkış Gazı & 9.699 & 587 & 0,38 & 2.163 .449 & 97,69 \\
\hline $\begin{array}{l}\text { Rekütüratöre Giren } \\
\text { Yakma Havası }\end{array}$ & 9.179 & $18^{*}$ & 0,31 & 51.253 & 2,31 \\
\hline $\begin{array}{l}\text { Reküperatördeki } \\
\text { Sızıntı Hava }\end{array}$ & 0 & $18^{*}$ & 0,31 & 0 & 0,00 \\
\hline Toplam & & & & 2.214 .702 & \\
\hline Çıkışlar & $\begin{array}{c}\text { Debi } \\
\left(\mathrm{Nm}^{3} / \mathrm{h}\right)\end{array}$ & $\begin{array}{c}\text { Sicaklık } \\
\left({ }^{\circ} \mathrm{C}\right)\end{array}$ & $\begin{array}{c}\mathrm{Cp} \\
(\mathrm{kcal} / \mathrm{Nm} 3 \mathrm{~K})\end{array}$ & $\begin{array}{c}\mathbf{Q} \\
\text { (kcal/h) }\end{array}$ & $\%$ \\
\hline Baca Gazı & 9.699 & 458 & 0,37 & 1.643 .585 & 74.21 \\
\hline Fırın Yakma Havası & 9.179 & 142 & 0,32 & 412.284 & 18.62 \\
\hline Diğer Kayıplar & & & & 158.833 & 7.17 \\
\hline Toplam & & & & 2.214 .702 & \\
\hline
\end{tabular}


Tablo 7. Tav firını toplam enerji ve kütle denkliği (Total energy and mass balance of the annealing furnace)

\begin{tabular}{|c|c|c|c|c|c|c|}
\hline \multicolumn{7}{|c|}{ Fırın Enerji ve Kü̈tle Denkliği } \\
\hline Girişler & $\begin{array}{c}\text { Debi } \\
\left(\mathrm{Nm}^{3} / \mathbf{h}\right)\end{array}$ & $\begin{array}{c}\text { Oksijen } \\
(\%)\end{array}$ & $\begin{array}{c}\text { Sicaklık } \\
\left({ }^{\circ} \mathrm{C}\right)\end{array}$ & $\begin{array}{c}\mathrm{Cp} \\
\left(\mathrm{kcal} / \mathrm{Nm}^{3} \mathrm{~K}\right)\end{array}$ & $\begin{array}{c}\mathbf{Q} \\
(\mathbf{k c a l} / \mathbf{h})\end{array}$ & $\%$ \\
\hline LNG (Yakma Isısı) & 506 & & & 8.414 & 4.257 .484 & 98,07 \\
\hline LNG (Duyulur Is1) & 506 & & 18 & 0,43 & 3.916 & 0,09 \\
\hline $\begin{array}{l}\text { Firına Giren Yakma } \\
\text { Havası }\end{array}$ & 9.179 & $21 \%$ & 18 & 0,31 & 51.253 & 1,18 \\
\hline Kütük & $13.900 *$ & & 18 & $0,11 * *$ & 28.523 & 0,66 \\
\hline $\begin{array}{l}\text { Reküperatördeki } \\
\text { Sızıntı Hava }\end{array}$ & 0 & & 18 & 0,31 & 0 & 0,00 \\
\hline Soğutma Suyu & 0 & & 0 & 1 & 0 & 0,00 \\
\hline Toplam & & & & & 4.341.177 & \\
\hline Çıkışlar & $\begin{array}{c}\text { Debi } \\
\left(\mathrm{Nm}^{3} / \mathbf{h}\right)\end{array}$ & $\begin{array}{c}\text { Oksijen } \\
(\%)\end{array}$ & $\begin{array}{c}\text { Sicaklık } \\
\left({ }^{\circ} \mathrm{C}\right)\end{array}$ & $\underset{\left(\mathrm{kcal} / \mathrm{Nm}^{3} \mathrm{~K}\right)}{\mathrm{Cp}}$ & $\begin{array}{c}\mathrm{Q} \\
(\mathrm{kcal} / \mathrm{h})\end{array}$ & $\%$ \\
\hline Kütük & 13.553 & & 1.050 & 0,16 & 2.276 .820 & 52,45 \\
\hline Baca Gaz1 & 9.699 & 8,64 & 458 & 0,37 & 1.643 .585 & 37,86 \\
\hline $\begin{array}{l}\text { Reküperatördeki } \\
\text { Sızıntı Hava }\end{array}$ & 0 & & 458 & 0,37 & 0 & 0,00 \\
\hline Tufal Kaybı $(\% 2,5)$ & 348 & & 1.050 & 0,16 & 58.380 & 1,34 \\
\hline Soğutma Suyu & 0 & & 18 & 1 & 0 & 0,00 \\
\hline $\begin{array}{l}\text { Diğer Kayıplar } \\
\text { (Açıklık kaybı, } \\
\text { duvar kaybı, } \\
\text { reküperatör yüzey } \\
\text { kaybı vb.) }\end{array}$ & & & & & 362.392 & 8,35 \\
\hline Toplam & & & & & 4.341 .177 & 100 \\
\hline
\end{tabular}

$* \mathrm{~kg} / \mathrm{h}, * * \mathrm{Kcal} / \mathrm{kg}^{\circ} \mathrm{C}$

4.ENERJİ TASARRUF POTANSIYYELLERİ VE YATIRIMLAR (POTENTIAL ENERGY CONSERVATION OPPORTUNITIES AND INVESTMENT)

\subsection{Potansiyel Tasarruf Alanları (Potential Energy Conservation Opportunities)}

\subsubsection{Fazla Havanın Azaltılması (Reduction of Excess Air)}

Tav firınında yapılan ölçümlerde fırının; fırın dizayn değeri olan optimum (\%10) hava fazlalık katsayısının üzerinde çalıştığı tespit edilmiştir. Fırın çıkışı (reküperatör öncesi) yapılan gaz analizinde, fırının optimum hava fazlalı katsayısının üzerinde çalışmasına rağmen baca gazı analiz sonuçlarında yüksek miktarda karbon monoksit (330 480 ppm) çıktığ1 da görülmüştür.

$\mathrm{Bu}$ durumun nedeni; fırın iç basıncının atmosfer basıncından düşük olması nedeniyle firına dışardan hava girmesidir. Reküperatör sonrası (baca hattına) damper konularak firın iç basıncı atmosfer basıncını üzerine çıkartılabilir (fırın içi efektif basınç: 0,5 mmSS'ye çıkarılarak bu problem çözülebilir).
Fırına dışarıdan hava girmeyeceği için fırın optimuma yakın hava-yakıt oranıyla çalıştırılabilir. Hava fazlalık katsayısının optimum değerine çekilmesi durumunda yapılacak enerji tasarrufu miktarı Tablo 8'de verilmiştir.

Tablo 8. Tav firınında fazla havanın azaltılması ile yapılacak tasarruf miktarı (Potential energy savings by reducing excess air in the annealing furnace)

Fazla Havanın Azaltılması ile Yapılacak Tasarruf Miktarı

\begin{tabular}{|l|c|}
\hline Fazla hava debisi $\left(\mathrm{Nm}^{3} / \mathrm{h}\right)$ & 4.073 \\
\hline Fazla hava oranı $(\%)$ & 79,77 \\
\hline Hedef fazla hava oranı $(\%)$ & 10 \\
\hline $\mathrm{Cp}\left(\mathrm{kcal} / \mathrm{Nm}^{3} \mathrm{~K}\right)$ & 0,34 \\
\hline Havadaki azalma $\left(\mathrm{Nm}^{3} / \mathrm{h}\right)$ & 3.563 \\
\hline Hava giriş sıcaklığ $1\left({ }^{\circ} \mathrm{C}\right)$ & 18 \\
\hline Baca gazı sıcaklığ $1\left({ }^{\circ} \mathrm{C}\right)$ & 458 \\
\hline Enerji tasarrufu $(\mathrm{Kcal} / \mathrm{h})$ & 533.132 \\
\hline Fırın yıllık çalışma süresi $(\mathrm{h})$ & 2.300 \\
\hline Yıllık enerji tasarrufu $(\mathrm{Kcal})$ & 1.226 .203 .188 \\
\hline Tasarrufun LNG karşılı̆̆ $\left(\mathrm{Nm}^{3} / \mathrm{h}\right)$ & 63,36 \\
\hline
\end{tabular}


4.1.2. Yüksek Kapasiteli Yeni Bir Reküperatör Kullanımı (Using a New Recuperator Which Has More Heat Transfer Area)

Mevcut reküperatörün 1sı transfer yüzey alanı yetersiz olduğu için baca gazı 1sısının çok büyük bir bölümü firın yakma havasına (taze havaya) aktarılamamaktadır. Baca gazı sıcaklığı "yoğuşma" sıcaklığı olarak belirlenen sınırın (110-120 $\left.{ }^{\circ} \mathrm{C}\right)$ altına düşürülmeden bacadan atılan bu enerji, yüksek verimli bir reküperatör ile fırına tekrar kazandırılabilir $[12,13]$. Fırının fazla hava miktarı düşürüldüğünde baca gazı debisi azalacak ve baca gazı sıcaklığı daha da yükselecektir. $\mathrm{Bu}$ durum göz önünde bulundurularak baca gazı debi ve sıcaklığına uygun (yeterli 1sı transfer yüzey alanına sahip) reküperatör kullanımı gerekmektedir. Reküperatör uygulamalarında baca gazı sıcaklığının düşürülmesinde karşılaşılan problemlerden biri yakma havası sıcaklığı arttığında yakma havasının özgül hacminin artması sonucu burnerden gönderilen havanın kütlesel debisinin azalmasıdır. Çalışma yapılan tav firınında bulunan burner'lerin katalog değerleri incelendiğinde yakma havası sıcaklığının $550^{\circ} \mathrm{C}^{\prime}$ ye kadar yükseltilmesine izin verildiği görülmüştür. Dolayısıyla burner üzerinde ayar yapılarak, yakma havasinın hacimsel debisinin artırılması sağlanacaktır. Burner'de yapılacak bu ayarlama ile yakma havası sıcaklığ $550^{\circ} \mathrm{C}$ 'ye kadar yükseltilebilecektir. Yüksek kapasiteli yeni bir reküperatör kullanımıyla yapılacak enerji tasarrufu miktarı Tablo 9'da verilmiştir.

\subsubsection{Tufal Kaybının Önlenmesi (Reducing Descaling)}

Çelik, haddeleme sıcaklığına kadar isıtıldığında oksijenin metal yüzeyi ile reaksiyona girmesi sonucu tufal meydana geldiği bilinmektedir. Meydana gelen tufal miktarı: firındaki hava fazlalık katsayısına, 1sıtma süresine, ısıtılan çeliğin kalitesine, firın atmosferine, 1sitma aparatlarının tip ve kullanım şekillerine bağlı olduğu belirtilmektedir [14-16]. Tav fırını çıkışı (reküperatör öncesi) yapılan gaz analizinde, fırına gönderilen yakma havası miktarının gereğinden fazla olduğu tespit edilmiştir. Yakma havası miktarı gereğinden fazla olduğunda, fırın sıcaklığı düşmekte ve hava fazlalığından dolayı tavlanacak malzemede tufal oluşup malzeme kaybı meydana gelmektedir. Ölçümler sonucunda Tav Fırınında tufal kaybı ortalama \%2,5'dir. Yapılan araştırmalarda bu değerin ortalama \%1,8-2'ye çekilebileceği anlaşılmıştır.

\subsubsection{Fırın yüzey kayıpları (Furnace Surface Heat Losses)}

Çalışma kapsamında fırın yüzey kayıplarının tespitine yönelik olarak firın yüzeyi termal kamera ile taranmış, eksik ve zayıf izolasyonlar tespit edilmiştir. İzolasyon kayıplarından kaynaklanan ısıl kayıpların toplamdaki payının düşük olduğu varsayımı ile yüzey kayıplarına yönelik hesaplama yapılmamıştır.

\subsubsection{Toplam Tasarruf Miktarı (Total Saving Amount)}

Yukarida belirtilen tasarruf potansiyellerinin değerlendirilmesi durumunda yapılacak toplam enerji tasarrufu ve bu tasarrufun mali karşılığı Tablo 10'da verilmiştir.

Tav fırını için belirtilen potansiyel tasarruf alanlarının uygulanması ile $\mathrm{CO}_{2}$ salınımındaki azalma Tablo 11 'de verilmiştir.

Tablo 9. Mevcut tav firını reküperatörünün yüksek kapasiteli bir reküperatör ile değiştirilmesi durumunda yapılacak tasarruf miktarı (Potential energy savings by changing the current recuperator with a high-capacity recuperator)

\begin{tabular}{|l|r|}
\hline \multicolumn{2}{|c|}{ Yüksek Kapasiteli Reküperatör ile Yapılacak Tasarruf Miktarı } \\
\hline Mevcut reküperatör çıkışı baca gazı sıcaklığ $\left.1{ }^{\circ} \mathrm{C}\right)$ & 458 \\
\hline Yeni imal edilecek reküperatör çıkışı baca gazı sıcaklığ $1\left({ }^{\circ} \mathrm{C}\right)$ & 180 \\
\hline Reküperatör çıkışı gazı debisi $\left(\mathrm{Nm}^{3} / \mathrm{h}\right)$ & 6.136 \\
\hline Cp $\left(\mathrm{kcal} / \mathrm{Nm}^{3} \mathrm{~K}\right)$ & 0,35 \\
\hline Enerji tasarrufu $(\mathrm{Kcal} / \mathrm{h})$ & 704.446 \\
\hline Firın yıllık çalışma süresi $(\mathrm{h})$ & 2.300 \\
\hline Tasarrufun LNG karşılığ1 $\left(\mathrm{Nm}^{3} / \mathrm{h}\right)$ & 83,72 \\
\hline
\end{tabular}

Tablo 10. Tav firını toplam tasarruf miktarı (Total amount of savings of the annealing furnace)

\begin{tabular}{|l|c|c|c|}
\hline \multicolumn{1}{|c|}{ Tasarrufun Adı } & $\begin{array}{c}\text { Enerji } \\
\text { (Kcal/h) }\end{array}$ & $\begin{array}{c}\text { Tasarrufun } \\
\text { LNG Karşılı̆̆ı } \\
\left(\mathbf{N m}^{\mathbf{3}} / \mathbf{h}\right)\end{array}$ & Yıllık Mali Değeri (USD) \\
\hline Fazla havanın azaltılması & 533.132 & 63,36 & 80.154 \\
\hline $\begin{array}{l}\text { Mevcut reküperatörün yüksek verimli (yüksek } \\
\text { kapasiteli) bir reküperatörle değiştirilmesi }\end{array}$ & 704.446 & 83,72 & 105.910 \\
\hline \multicolumn{1}{|c|}{ TOPLAM } & $\mathbf{1 . 2 3 7 . 5 7 8}$ & $\mathbf{1 4 7 , 0 8}$ & $\mathbf{1 8 6 . 0 6 3}$ \\
\hline
\end{tabular}


Tablo 11. Tasarruf alanlarının uygulanması ile $\mathrm{CO}_{2}$ salınımındaki azalma (Reduction in $\mathrm{CO}_{2}$ emissions by the application of saving areas)

\begin{tabular}{|l|c|c|c|c|}
\hline \multicolumn{1}{|c|}{ Tasarrufun Adı } & $\begin{array}{c}\text { Tasarruf } \\
\text { Miktarı } \\
\text { (kcal/h) }\end{array}$ & $\begin{array}{c}\text { Tasarrufun } \\
\text { LNG Eşdeğeri } \\
\text { (Nm } \mathbf{3} / \mathbf{h})\end{array}$ & $\begin{array}{c}\text { CO2 Salınımında } \\
\text { Azalma (kg/h) }\end{array}$ & $\begin{array}{c}\text { CO2 Salınımında } \\
\text { Azalma } \\
\text { (Yıllık, kg) }\end{array}$ \\
\hline Fazla Havanın Azaltılması & 533.132 & 63,36 & 127 & 292.100 \\
\hline $\begin{array}{l}\text { Mevcut reküperatörün yüksek } \\
\text { verimli (yüksek kapasiteli) bir } \\
\text { reküperatörle değiştirilmesi }\end{array}$ & 704.446 & 83,72 & 168 & 386.400 \\
\hline TOPLAM & $\mathbf{1 . 2 3 7 . 5 7 8}$ & $\mathbf{1 4 7 , 0 8}$ & 295 & 678.500 \\
\hline
\end{tabular}

4.1.6. Yatırımlar ve Geri Ödeme Süreleri (Investment and Payback Period)

Yukarıda hesaplanan potansiyel tasarruf alanlarından "fazla havanın azaltılması" ve "yüksek verimli reküperatörün imal edilmesi" ile yapılacak olan tasarruf miktarları için yatırım miktarları ve geri ödeme süreleri Tablo 12'de verilmiştir.

\section{SONUÇ VE ÖNERILLER (CONCLUSIONS AND RECOMMENDATIONS)}

Bir sanayi kuruluşun ait tav fırınında, fırın verimliliği ve tasarruf potansiyellerinin belirlenmesine yönelik ölçümler alınmıştır. Ölçümlerden elde edilen verilerden yola çıkarak kütle ve enerji denklikleri oluşturulmuştur. Fırında tespit edilen enerji tasarruf potansiyelleri; firınların yüksek hava fazlalık katsayılarında çalıştırılması (firına yarı mamul giriş ve çıkış kapaklarından hava girmesi), reküperatörün 1sı transfer yüzey alanının yetersiz kalması olarak belirlenmiştir.

Fırının optimum hava-yakıt oranıyla çalıştırılması için fırına brülörler dışından giren havanın girişinin engellenmesi gerekmektedir. Buna yönelik firın baca hattına damper konularak, firının atmosfer basıncından daha yüksek bir basınçta $(0,5 \mathrm{mmSS})$ tutulması sağlanmalıdır. Fazla havanın azaltılması için gerekli yatırım miktarı 10.000 \$ ve amortisman süresi 1,3 aydir.

Fırın çıkışında baca gazı sıcaklığının düşürülmesi için 1S1 transfer yüzey alanı daha fazla olan yeni bir reküperatöre ihtiyaç duyulmaktadır. Böylelikle baca gazı sıcaklığ $458^{\circ} \mathrm{C}$ 'den $120^{\circ} \mathrm{C}$ 'ye düşürülerek yıllık $150.910 \$$ tasarruf elde edilebilecektir. Yüksek 1S1 transfer alanına sahip reküperatör yatırımının amortisman süresi yaklaşık 4,6 aydır.

Fırına giren fazla hava miktarı azaltıldığında mevcut durumda \%2,5 olan tufal kayb1 \%1,8 2 mertebelerine indirilebilecektir. Enerji tasarrufuna yönelik firına uygulanacak önlemlerle yılda $678.500 \quad \mathrm{~kg} \quad \mathrm{CO}_{2}$ emisyon salımı önlenecektir.

\section{SEMBOLLER DİZINİ (NOMENCLATURE)}

$B$ : yakıt debisi $\left[\mathrm{Nm}^{3} / \mathrm{h}\right]$,

$c_{p 1}$ : tavlama öncesi kütüğün özgül 1sısı $\left[\mathrm{Kcal} / \mathrm{kg}^{\circ} \mathrm{C}\right]$,

$c_{p 2}$ : tavlanan kütüğün özgül 1sıs1 $\left[\mathrm{Kcal} / \mathrm{kg}^{\circ} \mathrm{C}\right]$,

$H_{u}$ : yakıtın alt 1 sil değeridir $\left[\mathrm{Kcal} / \mathrm{Nm}^{3}\right]$,

$m_{k}$ : tavlanan kütüğün kütlesel debisi $[\mathrm{kg} / \mathrm{h}]$,

$T_{1}$ : tavlama öncesi kütüğün sicaklığ $1\left[{ }^{\circ} \mathrm{C}\right]$,

$T_{2}$ : tavlanan kütüğün sicaklığ $\left.1{ }^{\circ} \mathrm{C}\right]$,

$Z$ : firından olan [\%] 1sıl kayıpları,

\section{KISALTMALAR (ABBREVIATIONS)}

LNG Sivılaştırılmış doğalgaz

PHAST Proses 1sitma değerlendirilmesi ve gözden geçirme arac1

TEP Ton eşdeğer petrol

\section{KAYNAKLAR (REFERENCES)}

1. McAllister, S., Chen, J. ve Fernandez-Pello, A. C., "Thermodynamics of Combustion", Fundamentals of Combustion Processes, $1^{\text {st }}$ Edition, Springer, USA, 18-20, 2011.

2. IEA, "Global Energy Trends", World Energy Outlook 2007 Edition, International Energy

Tablo 12. Tav fırını için gerekli yatırımlar ve geri ödeme süreleri (Necessary investments and payback period for the annealing furnace)

\begin{tabular}{|l|c|c|c|c|}
\hline \multicolumn{1}{|c|}{ Tasarrufun Adı } & Yapılacak Olan \\
Yatırım & $\begin{array}{c}\text { Yatırımın } \\
\text { Maliyeti (USD) }\end{array}$ & $\begin{array}{c}\text { Tasarruf } \\
\text { Miktarı } \\
\text { (USD) }\end{array}$ & $\begin{array}{c}\text { Yatırımın } \\
\text { Geri Ödeme } \\
\text { Süresi }\end{array}$ \\
\hline Fazla Havanın azaltılması & $\begin{array}{c}\text { Tav fırını çıkışı oksijen } \\
\text { ölçme sistemi }\end{array}$ & 10.000 & 95.151 & 1,3 ay \\
\hline $\begin{array}{l}\text { Mevcut reküperatörün yüksek } \\
\text { verimli (yüksek kapasiteli) bir } \\
\text { reküperatörle değiştirilmesi }\end{array}$ & $\begin{array}{c}\text { Yüksek verimli bir } \\
\text { reküperatör imali }\end{array}$ & 55.000 & 142.180 & 4,6 ay \\
\hline
\end{tabular}


Agency, 73-75, 2007.

3. Terzi, U.K. ve Baykal, R., "Efficient and effective use of energy: a case study of Tofas", Environmental Research, Engineering and Management, Cilt 1, No 55, 29-33, 2011.

4. Simsek, B., Simsek, E.H. ve Altunok, T., "Empirical and Statistical Modeling of Heat Loss from Surface of a Cement Rotary Kiln System", Journal of the Faculty of Engineering and Architecture of Gazi University, Cilt 28, No 1, 59-66, 2013.

5. $\mathrm{Xu}, \mathrm{C}$. ve Cang, D., "A Brief Overview of Low $\mathrm{CO}_{2}$ Emission Technologies for Iron and Steel Making", Journal of Iran and Steel Research, International, Cilt 17, No 3, 1-7, 2010.

6. Ertem, M.E., Sen, S., Akar, G., Pamukçu, C. ve Gurgen, S., "Energy Balance Analysis and Energy Saving Opportunities for Erdemir Slab Furnace \#3", Energy Sources, Part A, Cilt 32, No 11, 979-994, 2010.

7. Ertem, G., Çelik, B. ve Yeşilyurt, S., "Endüstriyel Tav Fırınlarında Isı Denkliği Hesaplamaları ve Enerji Verimliliğinin Belirlenmesi”, IV. Ege Enerji Sempozyumu, İzmir, 1-8, 21-23 Mayıs 2008.

8. Si, M., Thompson, S. ve Calder, K., "Energy Efficiency Assessment by Process Heating Assessment and Survey Tool (PHAST) and Feasibility Analysis of Waste Heat Recovery in the Reheat Furnace at a Steel Company", Renewable and Sustainable Energy Reviews, Cilt 15, No 6, 2904-2908, 2011.
9. Chen, W.H., Chung, Y.C. ve Liu, J.L., "Analysis on Energy Consumption and Performance of Reheating Furnaces in a Hot Strip Mill", International Communications in Heat and Mass Transfer, Cilt 32, No 5, 695-706, 2005.

10. Manatura, K. ve Tangtrakul, M., "A Study of Specific Energy Consumption in Reheating Furnace Using Regenerative Burners Combined with Recuperator", Silpakorn University Science and Technology Journal, Cilt 4, No 2, 7-13, 2010.

11. Kaya, D. ve Eyidogan, M., "Energy Conservation Opportunities in an Industrial Boiler System", J. Energy Engineering, Cilt 136, No 1, 18-25, 2010.

12. Kaya, D. ve Güngör, C., "Sanayide Enerji Tasarruf Potansiyeli-I", Mühendis ve Makina, Cilt 514, No 20-30, 2002.

13. Kaya, D. ve Güngör, C., "Sanayide Enerji Tasarruf Potansiyeli-II", Mühendis ve Makina, Cilt 515, No 1, 36-44, 2002.

14. Trinks, W., Mawhinney, M. H., Shannon, R. A., Reed, R. J., ve Garvey, J. R., "Industrial Furnaces", $6^{\text {th }}$ Edition, John Wiley and Sons, Inc., USA, 2004.

15. Mullinger, $P$. ve Jenkins, B., "Industrial and Process Furnaces", Butterworth-Heinemann, UK, 2008.

16. Topbaş, M. A., "Endüstri Fırınları", Cilt 2, Damla Matbaacılık, İstanbul, 1992. 
